\title{
Protecting Buildings From a Biological or Chemical Attack: actions to take before or during a release. LBNL-51959
}

Phillip N Price, Michael D Sohn, Ashok J Gadgil, William W Delp,

David M Lorenzetti, Elizabeth U Finlayson, Tracy L Thatcher, Richard G Sextro, Elisabeth A Derby, Sondra A Jarvis

February 5, 2003 


\section{Contents}

1 Introduction $\quad 5$

1.1 Organization of this report $\ldots \ldots \ldots \ldots$

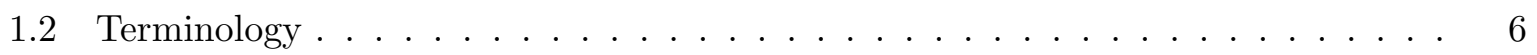

1.3 Acknowledgements . . . . . . . . . . . . . . . . . 7

1.4 Disclaimer . . . . . . . . . . . . . . . . . . . . . 8

2 Background $\quad 9$

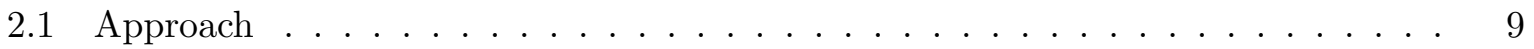

2.2 General assumptions . . . . . . . . . . . . . . . . . . . 10

2.3 Distinguishing between a chemical and biological release . . . . . . . . . . 11

2.4 Distinguishing between an indoor and outdoor release . . . . . . . . . . . 12

3 Outdoor release, biological or chemical $\quad 13$

4 Indoor release, biological or chemical $\quad 15$

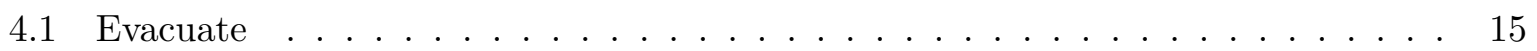

4.2 Congregate at a pre-determined assembly area $\ldots \ldots \ldots$

5 Indoor release, biological $\quad 17$

5.1 Limit the number of people exposed $\ldots \ldots \ldots \ldots$

5.2 Eliminate Exhaust of Contaminated Air . . . . . . . . . . . . . . . 18

5.2.1 Default Action: Shut off HVAC and close outdoor air dampers. . . . . . . 18 
5.2.2 Better than Default Action: Operate Building in Full Recirculation Mode If Previously Checked . . . . . . . . . . . . . . . . . . 19

5.3 Pressurize stairwells with outdoor air . . . . . . . . . . . . . . . . 20

5.4 Segregate exposed people . . . . . . . . . . . . . . . . . 20

6 Indoor release, chemical $\quad 22$

6.1 Goal: Minimize exposure . . . . . . . . . . . . . . . . . . 22

6.2 Default action: continue HVAC operation $\ldots \ldots \ldots \ldots$

6.3 Better than default action: Set HVAC to provide outdoor air . . . . . . . . . . 24

6.4 Best actions: Perform sophisticated HVAC manipulation . . . . . . . . . . . . 25

$\begin{array}{lll}7 & \text { Preparing for a biological or chemical attack } & 27\end{array}$

7.1 Actions that do not require changes to the building . . . . . . . . . . . 27

7.1.1 Prevent access to building air intakes . . . . . . . . . . . . . 28

7.1.2 Upgrade and maintain the HVAC system . . . . . . . . . . . . 28

7.1.3 Prevent access to building exhausts . . . . . . . . . . . . 28

7.1.4 Prevent access to HVAC equipment . . . . . . . . . . . . . . 29

7.1.5 Prevent access to building and HVAC plans . . . . . . . . . . . . . . . . . 29

7.1.6 Develop and train an emergency response team . . . . . . . . . . . . 29

7.1.7 Establish external congregation areas $\ldots \ldots \ldots \ldots$

7.1 .8 Plan and practice . . . . . . . . . . . . . . 30

7.2 Actions requiring changes to the building $\ldots \ldots \ldots$

7.2.1 Provide secure access to HVAC controls . . . . . . . . . . . . . . . 31

7.2.2 Provide separate exhaust systems for high-risk areas $\ldots \ldots \ldots \ldots$. . . . 31

$7.2 .3 \quad$ Upgrade filters . . . . . . . . . . . . . . . . . . . . . . 32

7.2.4 Establish internal safe zones . . . . . . . . . . . . . . . . . . . 32

7.2 .5 Weatherize the building . . . . . . . . . . . . . 33

8 Concluding comments $\quad 34$ 
A Facts about chemical warfare agents

B Facts about building operation 


\section{Chapter 1}

\section{Introduction}

This report presents advice on how to operate a building to reduce casualties from a biological or chemical attack, as well as potential changes to the building (e.g. the design of the ventilation system) that could make it more secure. It also documents the assumptions and reasoning behind the advice. The particular circumstances of any attack, such as the ventilation system design, building occupancy, agent type, source strength and location, and so on, may differ from the assumptions made here, in which case actions other than our recommendations may be required; we hope that by understanding the rationale behind the advice, building operators can modify it as required for their circumstances.

The advice was prepared by members of the Airflow and Pollutant Transport Group, which is part of the Indoor Environment Department at the Lawrence Berkeley National Laboratory. The group's expertise in this area includes:

- tracer-gas measurements of airflows in buildings (Sextro, Thatcher);

- design and operation of commercial building ventilation systems (Delp);

- modeling and analysis of airflow and tracer gas transport in large indoor spaces (Finlayson, Gadgil, Price);

- modeling of gas releases in multi-zone buildings (Sohn, Lorenzetti, Finlayson, Sextro);

- and occupational health and safety experience related to building design and operation (Sextro, Delp).

This report is concerned only with building design and operation; it is not a how-to manual for emergency response. Many important emergency response topics are not covered here, including crowd control, medical treatment, evidence gathering, decontamination methods, and rescue gear.

\section{$1.1 \quad$ Organization of this report}

Chapter 2 presents the approach used to generate the advice, and provides the historical background of our research. In addition, it describes the general assumptions about a biological or chemical attack, including characteristics of the biological or chemical agents and the buildings in which they are released. Finally, it presents means of determining whether a released agent is 
biological or chemical, which is important because the appropriate response can vary with the type of agent.

Chapters 3-6 present advice that depends on whether the source is a chemical or biological agent, and whether the source is indoors or outdoors. Specifically:

- Chapter 3-outdoor release, whether biological or chemical;

- Chapter 4-general advice for any indoor release, whether biological or chemical;

- Chapter 5- specific advice for an indoor biological release; and

- Chapter 6 - specific advice for an indoor chemical release.

Within each chapter, sections present individual pieces of advice. When the validity of the advice isn't obvious, we present the reasoning that led us to our recommendation, and often some discussion of alternatives that we considered and why we rejected them. We admit the possibility that our advice may not be optimal.

\subsection{Terminology}

AHU zone The part of a building served by a single Air Handling Unit (AHU).

Air Handling Unit Equipment that includes a fan, and usually heating and cooling coils; in normal operation the Air Handling Unit (AHU) forces air to flow through the ventilation ducts; other forces (such as wind) can also force air to flow through the system.

APT group A research group at Lawrence Berkeley National Laboratory whose members study airflow and pollutant transport (APT) in buildings; the authors of this paper are all in the APT group.

Biological Agent A virus, spore, or bacterium (possibly specifically designed for biological warfare) released with the intent to cause harm.

Building Operator A person with knowledge of, and control over, the building's HVAC system.

Chemical Agent A poisonous substance (possibly specifically designed for chemical warfare), released with the intent to cause harm.

Contagious Disease A disease that can be transmitted from one living being to another (e.g. smallpox). Contrast with "Infectious."

Common Return A duct or mixing chamber (e.g. a ceiling space used as a return air plenum) that draws air from several parts of a building, allows it to mix, and delivers it to one or more air handling units (AHUs).

EMCS Energy Management Control System; an integrated system for monitoring and controlling HVAC operation.

First Responder Someone who is expected to be among the first trained emergency workers to arrive on the scene of a biological or chemical attack. First Responders include firefighters, security guards, and police officers. 
HVAC The "Heating, Ventilation, and Air Conditioning" system-which usually includes air supply and return grilles, ducts, ventilation fans, heating and cooling equipment, and building exhaust grilles - that partially or fully controls the flow of air within a building and between the building and the outdoors.

Separately controlled devices, such as ceiling fans and bathroom or kitchen exhaust fans, although they should rightly be considered part of the HVAC system, are often not thought of in that way by building operators. For purposes of this document, we discuss these fans separately from the rest of the HVAC system.

Infectious Disease A disease caused by organisms that can multiply within the body. Not synonymous with "Contagious" (see above). A disease can be infectious but not contagious; pulmonary anthrax is an example.

Return Air Air that is drawn from the building by the HVAC system, through HVAC ducts or other means such as a ceiling plenum. Return air may be exhausted from the building, or recirculated into the building.

Stack Effect Buoyancy-driven vertical air flow between floors of a building, caused by a temperature difference between indoor and outdoor air; e.g. if indoor air is warmer than outdoor air, it will tend to rise and escape through the upper parts of the building shell, and be replaced by air entering the lower part of the building; the reverse occurs if indoor air is cooler than outdoor air.

Supply Air Air that is delivered to the building by the HVAC system, whether through ductwork or other means such as a ceiling or floor plenum. Supply air is normally a mixture of return air and air drawn from outside; once the air has passed through the AHU, it is termed supply air.

Transfer Air Air that passes from one ventilation zone to another due to HVAC system imbalance or other causes of pressure differences (e.g. imbalance caused by the stack effect).

Ventilation Zone For purposes of this document, this term is synonymous with "AHU zone" except for buildings in which several AHUs draw their air return from a common return. In those buildings, "a ventilation zone" is the part of the building served by all of the AHUs whose return air is mixed together in a common return.

Virulent Extremely dangerous even in small quantities; thus, a highly toxic chemical or a potentially fatal or debilitating biological agent.

\subsection{Acknowledgements}

We benefited from having our advice reviewed by colleagues with experience in the design and operation of commercial building ventilation systems, notably Cliff Federspiel and Fred Bauman, both from the University of California, Berkeley, and Craig Wray and Dale Sartor of Lawrence Berkeley National Laboratory.

We had helpful discussions with Sergeant Wayne Windman, a member of the Redondo Beach Police Department who produces (and uses) police training materials for the California Peace Officer Standards and Training Commission, Cal-POST. Sergeant Windman was particularly 
helpful in keeping us focused on boiling our advice down into specific recommendations, rather than giving advice that is watered down by caveats and unreasonable requirements of predecision information.

Conversations with then-LBNL Fire Chief Stacey Cox, and Les Putnam of the City of Berkeley Fire Department, were valuable for telling us what types of emergency response can be contemplated and on what timescales they might occur.

This work was supported by the Office of Nonproliferation Research and Engineering, Chemical and Biological National Security Program, of the National Nuclear Security Administration under U.S. Department of Energy Contract No. DE-AC03-76SF00098.

\subsection{Disclaimer}

Neither the United States Government nor the University of California nor any of their employees, makes any warranty, express or implied, including the warranties of merchantability and fitness for a particular purpose, or assumes any legal liability or responsibility for the accuracy, completeness, or usefulness of any information, apparatus, product, or process disclosed in this report. 


\section{Chapter 2}

\section{Background}

\subsection{Approach}

In early 1998, a group at the Lawrence Berkeley National Laboratory began to work on problems related to airborne biological and chemical attacks on buildings. While research on pollutant transport in buildings had long been conducted at LBNL, it had mainly focused on indoor air quality, occupant health, and the design and performance of ventilation systems.

The research effort, which is led by Ashok Gadgil and Rich Sextro, aims specifically at finding ways to protect building occupants against attacks using biological or chemical agents, through improved building or ventilation system design and through better operational response to attacks. Specific research areas include:

- finding ways to improve ventilation system design to reduce casualties from an attack;

- providing methods for characterizing an attack, especially its source location and source strength, while it is still underway;

- assessing building vulnerability and developing response plans for managers and operators of specific buildings;

- advising emergency personnel on how to respond to attacks in public buildings; and

- providing post-event analysis to help in cleanup and investigational efforts.

Most of the group's work comprised scientific research that others can apply in the futurewe are primarily a research group, not an application development team. For example, we developed new experimental methods and equipment for measuring the spread of a tracer gas (and thus the flow of air) in a large atrium, work that is important in producing accurate computer models of contaminant transport but that was not intended to lead immediately to new advice or methods of building operation. A more applied area of the group's research was an effort to provide information and/or advice for "First Responders" (police or firefighters) to a biological or chemical (CB) release. To this end a four-page informational document on building operation was produced (reproduced in Appendix B); updated versions will be maintained at http://securebuildings.lbl.gov.

In September, 2001, large-scale terrorist attacks in the United States added urgency to our work. The following month, a series of intentional anthrax releases, using envelopes sent through 
the mail as a delivery mechanism, made the fear a reality. It also brought sudden relevance to the LBNL "Information for First Responders" document. Sergeant Wayne Windman of the California Police Officer Standards and Training Office (Cal-POST) learned about the document and expressed interest in using it in training materials for police officers in California; the California police officer training materials are also used in about twenty other states.

To further address the needs of First Responders, in early 2002 the APT group had a series of working meetings to generated advice for dealing with a chemical or biological release. We started with some specific scenarios, such as "Ten minutes ago, a chemical canister in the lobby of a 7-story building began releasing a highly toxic gas. People in the lobby were immediately incapacitated. What should be done?" We used decision trees to work through possible responses (e.g. can the building be made to deliver $100 \%$ fresh air? If yes, do so; if no, go to the next question). We then examined the decision trees to identify which advice was generally appropriate and which would only be appropriate for particular building types or release scenarios. We also considered building and HVAC features that, if changed, would make the building safer, and emergency responses that could further reduce casualties.

Several rounds of discussion and review led to a fairly extensive set of recommendations, some of them aimed at building operators and some aimed at First Responders. These recommendations are presented on a web site, http://securebuildings.lbl.gov, which went online in mid-February, 2002. Some of the recommendations were incorporated into a slide presentation we prepared for Cal-POST, which they began using in mid-February in police officer anti-terrorist training classes[3].

This report describes the assumptions and reasoning that we applied, and presents our advice on how to prepare for, and act during, a chemical or biological release.

\subsection{General assumptions}

Our advice concerns an intentional biological or chemical release. We assume that a biological or chemical attack would release the agent to the air quickly (probably within a few minutes or less), that the agent would be virulent, that the attack would be unexpected and the release location may be unknown, and that the total mass of agent released into the air would be under about $10 \mathrm{~kg}$. and probably much smaller. (For comparison, a standard gas-grill propane tank has a capacity of about $20 \mathrm{~kg}$.). Some of our advice would differ in the case of the accidental release of a toxic industrial compound, such as a solvent spill (much less virulent, low mass, probably inefficiently released to the air via evaporation) or an industrial release (potentially much greater mass, probably less virulent).

The advice in this document applies to typical large commercial buildings with fairly ordinary HVAC systems: buildings with multiple air handling units, each supplying air to a separate area of the building and designed to draw return air from the same area that they supply. In practice, few HVAC systems work as designed: almost always, some air is carried between ventilation zones by pressure imbalances, including the stack effect and wind effects.

In some large buildings, each air handling unit supplies air to a different part of the building, but the return air enters a "common return" and is a mixture of air from several of these areas. In these cases, the HVAC system will spread contamination as if there were a single air handling 
unit serving all of the areas: contamination in one area will enter the return air and will be spread by all of the air handling units that draw from the common return. The advice in the present document will still apply to buildings that have this type of HVAC system, but in such buildings the term "ventilation zone" refers to all parts of a building that contribute air to the same common return, or, equivalently, all parts of the building that are served by the air handling units that draw air from the same common return.

Features such as sensors that can detect biological or chemical agents, computerized real-time sensor interpretation, and the full-time presence of a trained building operator at an HVAC control station, could allow much faster action and provide more knowledge on which to base decisions than we have assumed to be available. In such a case, we might suggest actions other than those given here. However, given the tiny fraction of the building stock that is prepared in that fashion, we think advice that applies to typical buildings is much more likely to be useful. Some of our advice may not be relevant for small buildings (although it will not be harmful). For example, the HVAC manipulations discussed in section 6.4 will probably not be helpful for a building less than about five stories high, because (1) such buildings usually have only a few AHU zones, so the agent will probably have spread through the whole building within five to fifteen minutes, which is likely to be sooner than HVAC manipulations can be performed; and (2) everyone who hasn't been incapacitated will probably have escaped the building before the HVAC operation can be changed.

\subsection{Distinguishing between a chemical and biological release}

Advice: If you know a release of some kind has occurred, determine whether it is a chemical release by looking for symptoms. A biological agent rarely causes immediate symptoms; a chemical agent almost always does.

Symptoms of exposure to toxic chemicals, including chemical warfare agents, include one or more of:

1. pinpoint pupils, leading to a perception of darkness;

2. dilated pupils (caused by some chemicals, but not chemical warfare agents);

3. dizziness;

4. runny nose;

5. clammy skin or perspiration;

6. difficulty breathing;

7. nausea and/or vomiting;

8. blurred vision or blindness;

9. seizures;

10. loss of bladder control;

11. loss of consciousness, or death.

If people in the building exhibit sudden onset of some of these symptoms, a chemical release may be responsible. Food poisoning could have some of the same symptoms but would usually not strike many people nearly simultaneously.

Biological agents may include spores, viruses, or bacteria, all of which are particles and can thus be removed by filters. Filter efficiency varies greatly with particle size and with filter type, 
an issue we discuss briefly in section 7.2.3.

Chemical agents may be gases or aerosols (tiny droplets). In either case, they will not be removed by conventional particle filters: even if the droplets are captured by a filter, the agent will evaporate and be dispersed as a gas. Special charcoal filters can remove chemical agents, but these are very expensive and are rarely installed in buildings.

\subsection{Distinguishing between an indoor and outdoor release}

The location of the source is a crucial piece of information, since actions will be very different for three different cases: (1) outdoor release, (2) indoor release, (3) release into the building air intakes.

Since a biological release will generally not cause immediate symptoms, knowledge of the location, and even occurrence, of a biological release will usually depend on either direct observation of the release event (e.g. powder falls out of an envelope), or a warning from a law enforcement agency or other source. Lacking such evidence, detecting the source for a biological release may not be possible.

However, whether the source of a chemical release is indoors our outdoors can usually be determined:

Advice: Except for a release near a building's air intake, it would take a very large or very toxic outdoor release to cause immediate severe symptoms indoors. Such releases are not impossible, especially for industrial accidents (e.g. Bhopal, India, in December 1984). If there is uncertainty as to where the release occurred or is occurring, look outside - if people are getting very ill inside from an outdoor source, then there will normally be visible evidence outdoors: dead or dying birds and wildlife, people collapsing on the sidewalks, etc. If these signs aren't present, the source is probably indoors, or in (or near) one of the building's air intakes. 


\section{Chapter 3}

\section{Outdoor release, biological or chemical}

Advice for outdoor release, when outdoor air is currently contaminated: For an outdoor release, whether biological or chemical, minimize exposures by taking as many of the following actions as possible:

1. keep people indoors;

2. close all windows and doors to the outside;

3. close all internal doors;

4. shut off all HVAC fans and close all HVAC dampers, including exhaust dampers;

5. shut off other fans such as kitchen and bathroom exhausts;

6. do not use elevators - they create a piston effect and can pump air into or out of the building

7. have people gather in pre-identified "shelter-in-place" rooms that have no or low air exchange with the outdoors, and have low air exchange with the rest of the building.

8. once the outdoor concentration has diminished to safe levels (as determined by emergency response teams), evacuate the building and flush it with outdoor air. After the contaminated plume passes, the concentration of contamination will actually be higher inside the building than outside, because the building will tend to retain contamination that managed to enter.

These conditions should be maintained until the outdoor concentration of contaminant has decreased to a safe level; at that point, the building should be evacuated.

The advice listed above is appropriate for almost all buildings. If the building is equipped with special filtration equipment, continued HVAC operation may be beneficial, as discussed below. 
Reasoning: Minimizing the rate of air exchange with the outside will keep the indoor concentration as low as possible for as long as possible. Closing windows and doors, shutting off the HVAC system, and eliminating the "pumping" effect of elevators will help advance this goal.

Normal operation of HVAC will exhaust some building air and pull in some outdoor air. If the outdoor air is contaminated, the HVAC system will spread the contamination throughout the building. Air exhausted from the building by exhaust fans will also be replaced by outdoor air. Shutting off HVAC fans and exhaust fans will help minimize the air exchange with the outside.

Even putting the system on full recirculation (if that is possible) is generally not as good as shutting off the HVAC, since duct systems and dampers normally allow substantial leakage.

Discussion: If a building has special filters that are very effective at removing the biological agent - filters with a MERV rating of about 13 or higher (see [2]) and correctly installed so that no air bypasses the filters - some protection can be provided by pressurizing the building with treated (filtered) air: clean air is supplied, and closed or partially closed HVAC exhaust dampers force air to escape the building through the building envelope via cracks around windows, etc. In a properly prepared building, this procedure can provide substantial protection, as long as pressurization is achieved for the entire building. In most buildings, operation of the HVAC system in any conventional mode (that is, not specifically designed to pressurize the building) will increase the infiltration of unfiltered air, compared to turning off the system.

Special filters are also available that provide protection against a chemical release. These are very expensive and are normally installed only in buildings that are perceived to be at high risk. If such filters are installed and if the building is positively pressurized with respect to the outdoors, continued HVAC operation may be beneficial in the event of an outdoor chemical release.

In some unusual cases, continued HVAC operation could be beneficial even if the building does not have special filters. For example, if there is a release close to the ground near a tall building, and if the building's air intakes are on the roof or upper floors of the building, operating the HVAC so as to pressurize the building with air taken in through the HVAC system will usually be better than shutting off the HVAC. Actions such as this can only be taken if the building operator has very good knowledge of the release location and the dispersion of the contamination.

Another case in which continued HVAC operation may be beneficial involves a biological agent that has already spread through the building, as may occur if either an outdoor or indoor release occurred at least an hour before the building HVAC operation was stopped. In this case, and if the outdoor concentration has already diminished, the operation of the HVAC system will circulate the building's air through the HVAC filters, thus helping to remove the airborne agent. Even conventional filters, which often have a MERV rating of 9 or lower, will trap some bio-agent particles with each pass through the filters. Whether this approach is beneficial will depend on the outdoor concentration of the agent, and the filter effectiveness. 


\section{Chapter 4}

\section{Indoor release, biological or chemical}

The advice in this chapter is appropriate for any indoor release, whether the agent is biological or chemical. In addition to this advice, advice that is specific to indoor release of a biological agent is given in chapter 5 , and advice that is specific to an indoor chemical release is given in chapter 6 .

\subsection{Evacuate}

Advice: For an indoor biological or chemical release, evacuate people unless doing so will clearly expose them to additional danger.

Reasoning: During an indoor release or a release into a building's air intakes, the concentration of the chemical agent inside the building will be much higher (typically tens to thousands of times higher) than outside. Once people are outside and upwind of the building, their exposure to the airborne agent will stop; exposure to agents (especially biological agents) from clothes and skin may continue.

Discussion: People upwind from a contaminated building will no longer be exposed. However, evacuation will often require people to use stairways and hallways, which may tend to be more heavily contaminated than closed offices, especially if no HVAC manipulations are performed (or if inappropriate manipulations are performed); see Section 6.2. Also, although exposure from an indoor release will basically end once people are outdoors and upwind of the building, there is still the possibility of a secondary attack, such as a car bomb, targeting the evacuees. Both the chance of extra exposure during evacuation and the possibility of danger once outside are implicit in the suggestion that people should only be evacuated if this can be done "without exposing them to danger," but in practice there may be no good way to evaluate these risks.

A biological attack, particularly in a building in a busy city, introduces an additional danger: evacuation could transport the agent outdoors, possibly contaminating passers-by. This could greatly increase the number of people exposed, and worse, could expose people unknowingly, so they may not seek prompt medical attention. Evacuees should ideally not leave the scene (especially in the case of a biological release), but some are likely to do so before the agent can be fully evaluated and treated, and it is unrealistic to expect that passers-by can all be identified and 
detained if necessary. This leads to direct risk to the passers-by, but also potentially increases the chance of starting an epidemic if the disease is contagious.

On the other hand, failure to evacuate could expose many more people in the building. Without evacuation, release of a weaponized biological agent in, say, the mailroom of a skyscraper, may eventually expose a large portion of the building population, since the agent will eventually be carried everywhere by air flowing between ventilation zones. For a highly treatable agent such as anthrax it might be reasonable to treat everyone in the building anyway. For agents that cannot be treated so effectively (such as weaponized Ebola, if it exists), delay in evacuation may lead to the exposure of additional people, which may in turn cause unnecessary deaths.

On balance, we think that evacuation is the recommended option unless it will clearly expose occupants to additional danger.

\subsection{Congregate at a pre-determined assembly area}

Advice: Have evacuees congregate at one or two meeting points upwind from the building, and at least 30 meters (100 feet) from the building (preferably much farther). Separating people known to be exposed from those who may not have been exposed is also desirable as early as possible; having evacuees congregate by floor may be a workable solution.

Reasoning: We recommend congregating so that people can be accounted for (to avoid needlessly sending searchers into the building), first aid or treatment for chem/bio-agent exposure can be administered, and exposed people can be separated from passers-by.

We suggest a distance of at least 30 meters because local air flows and eddies around large buildings can carry the agent against the prevailing wind direction. A much greater distance should be used if possible, to protect against changes in wind direction.

Discussion: Another option would be to recommend that evacuees disperse as far and as fast as possible. This would make a secondary attack (e.g. a car bomb) less effective, and would ensure that people aren't vulnerable if the wind changes.

Overall, we think the need to locate, communicate with, decontaminate, and treat evacuees argues for setting up a meeting point. 


\section{Chapter 5}

\section{Indoor release, biological}

Chapter 4 gives advice that should be carried out whether the indoor release is of a biological or chemical agent. The present chapter gives additional advice that is specific to a biological release; see chapter 6 for advice that is specific to a chemical release.

A biological agent will probably not cause immediate symptoms, and the type of bio-agent (or even whether it is real or a hoax) may not be known for hours or possibly days after release. In fact, it is possible that a bio-agent can be introduced into a building without the occupants even knowing about it.

Obviously, if the building occupants don't know about the release, they can't respond to it. Our advice assumes a release is known or suspected to have occurred within the past hour or two.

This chapter gives detailed advice and reasoning for the following recommended actions:

1. Limit the number of people exposed;

2. Close HVAC dampers and turn off all fans;

3. Pressurize stairwells with outdoor air;

4. Segregate exposed people.

\subsection{Limit the number of people exposed}

Advice: For a biological release only, limit the total number of people exposed and make sure you know who has been exposed, even if pursuing these goals leads to higher exposure for some people.

Reasoning: If the disease caused by the agent is treatable, then keeping the number of exposed people low, and making sure they can all be found, ensures that everyone who needs treatment can get it. Most (though not all) treatable diseases can be successfully treated whether the exposure to the biological agent was to a high or low dose. 
If the disease is untreatable, it is even more important to reduce the total number of people who become ill. If exposure leads to a contagious disease with the potential to cause an epidemic, then being able to identify everyone who has been exposed is critical.

Discussion: Our recommended actions are intended to reduce the total number of people exposed - especially those exposed without knowing it - but are likely to increase the amount of agent to which some building occupants are exposed. This additional exposure may lead to increased health effects, or perhaps even death, among these building occupants. For instance, anthrax is normally very treatable if treatment starts soon enough after exposure - within a few days for moderate exposure, or a few hours for an exceptionally large dose-but inhalation of very large numbers of anthrax spores can make the illness untreatable [7]. It would be better to allow exposure of a lot of people to moderate numbers of spores (if they can all be found and treated) than to expose a few people to a massive dose.

We think that it there will usually be fewer occurrences of death or illness if the total number of exposed people is minimized and they are treated, compared to exposing a larger number of people to a smaller dose, if the latter would also expose some people unknowingly. However, this advice should certainly be subject to careful scrutiny.

\subsection{Eliminate Exhaust of Contaminated Air}

To minimize the risk to people outside the building (and thus to minimize the risk of epidemic), exhaust of contaminated air to the outdoors should be prevented. Depending on the building's exhaust system, this may be done in two ways:

1. Default Action: Shut off HVAC and close outdoor air dampers.

2. Better-than-default action: If the system has been suitably designed and tested, close exhaust dampers and intake dampers but let HVAC operate so as to circulate air through the filters.

We discuss each of these in more detail, below. No matter what HVAC actions are taken, everyone in the building - even a large building - should be considered to have been potentially exposed. It would be better to have to treat all occupants of the target building than to try to reduce the number of occupants exposed (or the magnitude of their exposure), at the risk of unknowingly exposing others. "Unknowingly" is the key - although the desire to minimize the number of exposed people is a motivating factor, the main point is to make sure that you can treat and/or quarantine everyone who has been exposed, or at least as high a percentage of those people as possible.

\subsubsection{Default Action: Shut off HVAC and close outdoor air dampers.}

Minimize the exhaust of contaminated air to the outdoors, by shutting off the HVAC system and closing outdoor air dampers. Local exhausts, such as those serving bathrooms and kitchens, should also be shut off; they are often controlled separately from the HVAC system. 
Reasoning: Operation of any HVAC system will exhaust air (and bio-agent) to the outdoors, possibly infecting people who don't know they are at risk.

Discussion: Whether exhausting biological contamination to the outdoors is dangerous depends on several factors, including the concentration of the agent, its virulence, its ability to survive travel through the air (e.g. susceptibility to ultraviolet exposure from sunlight; temperature; humidity), and the number of people downwind. Releasing moderate amounts of short-lived spores or bacteria may be fairly safe in an sparsely populated area, but the same release might be disastrous in the center of a city. Overall, since most large buildings are in fairly dense areas, there is a significant possibility of infecting someone outside (or in a nearby building that pulls contaminated air into its intake).

Shutting off the HVAC system may cause some discomfort to people in the building, in particular thermal discomfort (the people may become uncomfortably hot or cold), but there is no risk from oxygen deprivation or from carbon dioxide build-up for many hours, and probably no risk for any duration.

Shutting off the HVAC may also expose more people in the building to the biological agent, and may increase the exposure of people in contaminated areas of the building. On the other hand, the HVAC system can also act to spread contamination throughout the building, so shutting off the HVAC may reduce the number of people exposed.

The relative benefits of terminating or continuing HVAC operation will depend on many factors, such as the treatability of the agent; its contagiousness; the size distribution of the agent's particles and how effectively they are removed by the building's filters; the airborne concentration and its variation within the building; and so on.

\subsubsection{Better than Default Action: Operate Building in Full Recirculation Mode If Previously Checked}

Many buildings are designed so that some air is always exhausted during HVAC operation, and even in buildings with exhaust dampers that are designed so that they can be closed completely, these often do not function fully and thus cannot be closed completely. In either case, continued HVAC operation will exhaust contaminated air to the outdoors, potentially exposing unsuspecting people (perhaps in large numbers) to exposure.

However, in some buildings, the HVAC system can be set in a "full recirculation" mode that does not exhaust air from the building. Note that such an operational mode requires shutting both the exhaust and the intake dampers, since closing the exhaust dampers alone, with intake dampers open, will pressurize the building; this will cause contaminated air to escape through doors, windows, and cracks in the building shell, possibly exposing people outside the building.

If the building does have a full recirculation mode, then we recommend operating in that mode in the case of an indoor biological release, because this will allow the building's filters to remove airborne contamination without exposing people outside the building. This will be especially beneficial if the HVAC filters are very effective (MERV rating of 13 or higher), but will still provide some benefit even with typical filters. This action is recommended only if the effectiveness of the building's recirculation mode has been confirmed: in many buildings, exhaust dampers do not close completely, so even if the building is put into a mode that ought to cause 
full recirculation can lead to exhaust of significant amounts of outdoor air.

\subsection{Pressurize stairwells with outdoor air}

Advice: Pressurize stairwells with 100\% outdoor air to provide a safe evacuation route.

Reasoning: It will normally not be practical to confine people for a very long time in a building where a bioagent release is suspected. Also, for an indoor release, concentrations outside will probably be very low (especially if the HVAC has been shut off and/or if people evacuate to a collection point upwind of the building), so evacuation will reduce exposure if the concentrations in the evacuation routes are not high. Pressurizing stairwells - a key evacuation route - with outdoor air will prevent contaminated air from being pulled into the stairwells, as often can happen due to the "stack effect." All other ventilation fans should be shut off so the building doesn't become a significant source; of course, if the stairways are pressurized and other ventilation is not provided, the building will be at positive pressure with respect to the outdoors, on average, so some air will leak out of the building. Wind pressures and the stack effect will also cause air to leak out of some parts of the building, and into other parts.

Discussion: This advice represents a balance between two competing goals: to prevent exposing people outside, and to minimize exposure to people inside. As discussed in section 5.2, attempting to provide substantial amounts of outside air to the entire building would lead to large volumes of air, including contaminated air, being exhausted from the building. In our judgment, the moderate reductions of exposure of people indoors would not be worth the risk of unknowingly exposing people outside.

In contrast, stairwells represent a very small fraction of total building volume - typically less than 3\% - but during evacuation of a large building they will represent most of the personminutes during which people can be exposed. Providing outdoor air to the stairwells during evacuation can significantly reduce exposure of people inside without exhausting large amounts of heavily contaminated air. We think that pressurizing the stairwells during a biological attack will usually be beneficial.

\subsection{Segregate exposed people}

Advice: Segregate people known to be exposed, to avoid contaminating others via contact with clothes or skin, and tag or mark these people for medical treatment and decontamination.

Reasoning: For many agents and release scenarios, everyone in the building will likely be treated in any case. (In response to releases from a few envelopes containing anthrax, over 10,000 people were given antibiotics in the late-2001 anthrax attacks in Washington, D.C.) However, for some bio-agents treatment may be elaborate and costly, or adequate medications may be unavailable, so it may be necessary to treat only the people most likely to have been exposed. These people may also require decontamination measures such as removal of clothes, and disinfectant showers, that it may be impossible or impractical to give to the several-thousand-person population of a large office building. 
Moreover, lack of segregation may allow the agent to spread to others who don't know they have been exposed, such as passers-by on the street. It may be difficult or impossible to find these people later. 


\section{Chapter 6}

\section{Indoor release, chemical}

Chapter 4 gives advice that should be carried out whether the indoor release is of a biological or chemical agent. The present chapter gives additional advice that is specific to a chemical release; see chapter 5 for advice that is specific to a biological release.

Detailed advice and reasoning is presented in this chapter for the following recommended actions:

1. Minimize exposure;

2. Choose the appropriate HVAC action:

Default: continue HVAC operation

If building operator has checked operation: Set HVAC to provide outdoor air;

Best action: Perform sophisticated HVAC manipulation.

\subsection{Goal: Minimize exposure}

Advice: For a chemical release (but not a biological release), the goal is to minimize the exposure for everybody by exhausting contaminated air from the building and replacing it with outdoor air.

Discussion: Low air exchange rates between indoors and outdoors make an indoor chemical attack much more effective than one outdoors. Once the contaminated air is evacuated from the building, it will rapidly be diluted and become much less harmful. The contaminated air that is expelled from the building will be replaced, in full or in part, by uncontaminated air, thus reducing exposure for people still in the building. Some contaminated air may re-enter the building, depending on the location of the building air intakes relative to the exhausts, the prevailing wind direction and speed, etc.

As we discuss in section 6.2, alternatives to exhausting contaminated air have been suggested. There is tension between the goals of providing uncontaminated air to people who have already been exposed and providing continued uncontaminated air to people in the building who haven't 
been exposed. In practice, the optimal approach may vary depending on the details of the building and the release scenario, but we think that more often than not the basic approach should be to get the chemical agent out of the building quickly, although some subtleties are discussed below.

\subsection{Default action: continue HVAC operation}

Advice: It is best to leave the HVAC system operating without alteration, unless a knowledgeable building operator is available to perform HVAC manipulations such as those described in the following sections.

Reasoning: Under normal operation, the HVAC system will provide some outdoor air and will exhaust some indoor air, so it will help dilute the chemical and exhaust it from the building. Also, most buildings are designed to minimize flows between HVAC zones, a process known as "balancing." Although total system balance is rarely achieved, even partial balancing helps isolate zones that are served by different air handling units (AHUs), and will help slow the spread of contamination between zones.

Discussion: This advice is non-obvious, and indeed, some publications give advice that disagrees with ours. For example, the US Army Corps of Engineers [15] suggests "shut down all air-handling units until the type of hazard and extent of its spread can be determined."

We assume an intentional chemical release will likely occur quickly (so as to minimize the chance of detection before substantial harm has occurred), with most of the material being released within seconds or minutes of initiation. A ventilation system under normal operation will spread the agent through the entire zone served by an air handling unit rather quicklytypically within five to fifteen minutes. So, unless the air handling unit is shut off within the first few minutes of the release, shutting it off will usually not decrease the exposure for people within that AHU zone. Additionally, shutting off the AHU will substantially slow the supply of outdoor air (all HVAC systems supply some fresh air), thus tending to increase the exposure of people who remain in the zone.

Most building HVAC systems are not properly balanced when operating, but we think that shutting off the HVAC, or a single air handling unit, will tend to increase imbalances, pulling contaminated air from the affected zones into other zones. This assumption may be incorrectthere is little available data on HVAC system balance, and such data as exist are usually for newly commissioned buildings.

Whether or not the HVAC is operating, an important driving force, especially in buildings taller than a few stories, is the "stack effect": if the indoor air is cooler than outdoors, building air will tend to flow out through the bottom levels of the building and be replaced by air coming in the top, and vice versa if the indoor air is warmer than outdoors. These vertical flows may draw contaminated air into the vertical connections between floors, notably the elevator shafts and stairwells, which also provide the main evacuation routes. Particularly in very tall buildings during winter, the stack effect can create pressure differences so large that elevator doors don't function properly, stairway doors can be difficult to open, and air flows in elevator shafts and stairwells can be substantial, especially, in the case of stairwells, when some doors are open [9]. These effects are strongly dependent on the leakage area (the total area of cracks and openings) 
in the upper floors of the building, and thus could be exacerbated if people open, or break, windows on the upper levels of the building in an attempt to ventilate with outdoor air.

In most buildings the HVAC system can be set to reduce vertical airflows caused by the stack effect (e.g. by pressurizing the upper floors relative to the lower floors when the outdoor temperature is low, or by maintaining a pre-set pressure relative to the outdoors on each floor). Unfortunately we do not know what fraction of buildings are actually set that way, or even whether the fraction is over or under $50 \%$. When a building is set so that HVAC partially counteracts the stack effect, it is usually an unintended consequence of HVAC testing and balancing procedures (such as those described in [1]). Building modifications, such as airtight partitions in stairwells and airtight vestibules around entrance doors, can help reduce flows caused by the stack effect, as discussed in [9].

As discussed below, a trained and knowledgeable building operator can take beneficial actions, but we think that the benefits of continued HVAC operation - supply of fresh air, exhaust of the chemical, and retaining HVAC balance - will usually be better than simply shutting off the system (or parts of it).

The recommendation might be different for a slow release that continues for a long time. In that case, shutting off the relevant AHU would help slow the spread of the agent before it is thoroughly mixed through the ventilation zone. We think a slow release is unlikely for an intentional attack. A slow release is more likely in an accident such as a solvent or paint spill, but in most commercial buildings these latter types of contaminants would be unlikely to cause immediate severe health effects, because the contaminants, though toxic, would typically be much less toxic than a chemical warfare agent. For most accidental releases, continued HVAC operation coupled with immediate evacuation, though perhaps not optimal, would not be disastrous.

\subsection{Better than default action: Set HVAC to provide outdoor air}

Advice: If the building operator has previously checked system operation and is sure that dampers and fans are working correctly, set the HVAC to supply $100 \%$ outdoor air.

Reasoning: This will rapidly dilute the agent and exhaust it from the building, without spreading it via the HVAC system. This will normally be better than unchanged HVAC operation, which typically recirculates some contaminated air.

Discussion: Having the HVAC system deliver $100 \%$ outdoor air will rapidly dilute the chemical inside the building by forcing contaminated air to the outside. Concentrations near the building exhausts may be high, and could potentially be high enough to injure (or even kill) people downwind of the building. Contaminated exhaust air can re-enter the building through the air intakes, a phenomenon that can be greatly reduced through good ventilation design (see [10]). Also, in a city, contaminated air exhausted from the target building could be pulled in by the HVAC systems of nearby buildings; in that case, those nearby buildings should treat the event as an outdoor release (see chapter 3 ).

The exhaust air from a contaminated building will create an airborne plume of contamination 
downwind. The plume will spread out with distance, and thus its concentration will decrease. In mild winds $(3 \mathrm{~m} / \mathrm{s})$ over flat ground, at $100 \mathrm{~m}$ from an exhaust damper $2 \mathrm{~m}$ on a side, the plume will spread to occupy roughly 20 meters horizontally and 10 meters vertically (see [13], p.544, 575-576), representing dilution by about a factor of 50. This probably underestimates the amount of dilution, since additional turbulence induced by changes in wind speed and direction, or by eddies around objects, would cause the plume to spread and dilute more rapidly; dilution by a factor of several hundred is possible in $100 \mathrm{~m}$.

\subsection{Best actions: Perform sophisticated HVAC manipulation}

Some beneficial HVAC manipulations can only be performed by someone with fairly extensive knowledge about the operation of the building, including knowing which air handlers serve which ventilation zones and how to control dampers to close off supply to some areas. These actions can potentially greatly reduce the chemical exposure of people in areas of the building that have not yet been contaminated.

1. The operator should be aware of the possibility of a source in the building air intakes, and should shut off the supply from any intake in which this is thought to have occurred.

2. Pressurize stairwells with $100 \%$ outdoor air;

3. Put the air handlers that serve heavily contaminated areas onto full exhaust and shut off supply to those areas;

4. Supply $100 \%$ outdoor air to uncontaminated areas and areas with people in them.

Many buildings have a smoke control or smoke removal system (see [1]) that facilitates performing actions 2-4 If such a system is present, it should be used; it will probably be very effective. Smoke removal systems often have their own duct-work and exhaust registers, rather than using the HVAC system; in such cases, it is the smoke system's exhaust ducts that will act as sources of agent to the outside.

Although chemical contamination can be removed effectively using a smoke control system, it differs from smoke in an important way: unlike smoke, chemical warfare agents are not buoyant. Smoke infiltration barriers that rely on buoyancy will not be effective, and staying low to the floor will not generally reduce occupant exposures.

Reasoning behind Item 2: Pressurizing stairwells will help provide a safe evacuation route. For a large building, during evacuation the total number of person-minutes spent in the stairwells is likely to be very high: almost everyone will need to use a stairwell, and each person may spend more time in the stairwell than in other areas of the building combined. Many buildings already have equipment that can pressurize the stairwells with outdoor air, since this is a standard fire safety technique.

Reasoning behind Item 3:. Isolating the contaminated zones by shutting off supply to those areas while maintaining exhaust will de-pressurize those areas relative to the rest of the building, and thus force air to flow from safe areas to contaminated areas rather than the other way around. 
Discussion of Item 3: In most commercial buildings, the ventilation system will spread contamination through an entire ventilation zone within less than fifteen minutes, and often less than ten, which we think is much sooner than HVAC would be manipulated in an ordinary building. By the time the HVAC response is initiated, people in the highly contaminated areas will already have been exposed for many minutes. For a chemical agent, any people still present in the highly contaminated areas by the time HVAC manipulation is performed presumably became incapacitated soon after the initial exposure; otherwise they would have escaped. For these people to have been incapacitated for a long time, the release must be at dangerously high concentrations, and should not be allowed to spread into areas that still have people in them. The highest priority should be to prevent spreading the agent into other areas rather than to deliver the maximum possible amount of fresh air to the already incapacitated people.

Even with air handlers that serve contaminated zones set to full exhaust, and supply dampers closed, uncontaminated air will still be delivered to the contaminated zones: the zones will draw air from adjacent uncontaminated zones and from the outside through the building shell. However, the supply of air will be less than if these zones were delivered supply air by the HVAC system.

Reasoning behind Item 4: Providing 100\% outdoor air to uncontaminated areas will ensure that the people in these areas remain safe, especially if this action is coupled with putting the contaminated areas on full exhaust. 


\section{Chapter 7}

\section{Preparing for a biological or chemical attack}

In the previous sections, we discussed actions that can be taken during a biological or chemical attack to reduce casualties in a large commercial building. In this section, we discuss actions that can be taken before an attack, both to make the building inherently safer and to enable faster and more appropriate response to an attack. We break these actions into two classes: actions that can be taken without modifying the building, and actions that require modifications (such as changes to the HVAC system).

Our advice on preparing for an attack is less debatable than our advice for what actions to take during an attack, so for this section we do not separate the text into advice, reasoning, and discussion.

\subsection{Actions that do not require changes to the building}

The following actions, fleshed out in detail below, are inexpensive (for most buildings) and can be effective, and should be considered for any building:

1. Prevent access to building air intakes;

2. Upgrade and maintain the HVAC system;

3. Prevent access to building exhausts;

4. Prevent access to HVAC equipment;

5. Prevent access to building and HVAC plans;

6. Develop and train an emergency response team;

7. Establish external congregation areas;

8. Plan and practice responding to a release; 


\subsubsection{Prevent access to building air intakes}

A terrorist can quickly contaminate a building with a biological or chemical agent by introducing it into the building's ventilation system. This can be done even without access to the interior of the building through the building's air intakes. Some buildings have air intakes that are difficult to access (e.g. on the roof), but many others have intakes that are easily accessible and thus vulnerable.

Keeping the public a short distance away from the air intake may not prevent introduction of a chemical or biological agent. For instance, a plastic bag containing anthrax spores could be tossed into an air intake from some distance away. Many air intakes have baffles or louvers, which can make this type of attack less likely to succeed if the air intakes are not directly accessible. Louvers or other devices may be added to existing unprotected intakes, but they might affect the amount of outdoor air that can be pulled in by the building, and the energy efficiency with which this can be done, so they should be installed only after careful evaluation.

The best method of preventing access to air intakes depends on the the building's design and its physical relationship to publicly accessible areas. Possibilities include fencing off outdoor areas near air intakes, or restricting access to the grounds on which the building sits. If the building has a video surveillance system, air intakes can be monitored.

If the threat to the building is high and it is not feasible to prevent access to the air intakes, either moving the intakes or extending them vertically should be considered. The National Institute of Occupational Safety and Health suggests guidelines [6] for relocating or elevating air intakes.

\subsubsection{Upgrade and maintain the HVAC system}

Check and repair the HVAC system to ensure proper operation, including system balance, and correct operation of the building's economizer mode (if any). Dampers should be checked for proper operation and for leakage, and replaced or repaired if necessary. In addition to making the building safer in the event of a chemical or biological attack, such repairs could significantly reduce energy costs.

Make sure building operators can quickly manipulate HVAC systems to respond to different types of attack. It should be possible to quickly shut off the HVAC system (including closing dampers that admit outdoor air and closing exhaust dampers), or to put the system on $100 \%$ fresh (outdoor) air. Consider installing sensors that can confirm that the desired action has actually occurred.

The National Institute of Occupational Health and Safety gives a more complete list of HVAC upgrades and maintenance; see [6].

\subsubsection{Prevent access to building exhausts}

A substantial fraction of large commercial buildings sometimes take in substantial amounts of outdoor air through what are intended to be the building exhausts $[11,12]$. This phenomenon, 
which is contrary to the intent of the building designers and is often not recognized by building operators, is much more likely to occur during hot weather than at other times.

Building exhaust registers may be more accessible to terrorists than are building air intakes, since building designers often assume that there can be no inward flow through these registers, and thus place them anywhere convenient. Common cases include exhaust registers located on or adjacent to loading docks, or sidewalks.

Setting the building HVAC for full exhaust will be highly effective at preventing a chem/bio agent from entering through the exhaust registers, once the release has been detected. However, preventing access to these registers in the first place, if it is practical to do so, would be a more effective measure, for buildings that sometimes draw air through the exhaust registers.

\subsubsection{Prevent access to HVAC equipment}

A terrorist with access to a building's HVAC equipment can quickly contaminate the entire building, or at least an entire ventilation zone, with a biological or chemical agent. The rooms that contain HVAC equipment should be locked and keyed so that they can be opened only by authorized staff.

Many release scenarios, such as a release into an HVAC return plenum, rely on the HVAC system to quickly distribute the agent even if the equipment itself is not accessible; however, access to the HVAC equipment would enable a terrorist to put the building into the most damaging possible operating mode, e.g. by closing dampers and operating fans so as to expose the largest number of people to the highest possible concentrations. Also, a terrorist could damage control actuators so that the HVAC operation to reduce casualties cannot be performed after the release has been detected.

\subsubsection{Prevent access to building and HVAC plans}

A terrorist who wants to maximize the casualties from an indoor chem/bio attack, or to target specific people, can use knowledge of the building's ventilation system, such as how many ventilation zones the building has, and which air vents serve which rooms, etc. The easiest way to determine these facts is from the building plans.

Access to building plans and ventilation system details should be controlled. If plans are provided to contractors for building work, they should be recovered after use whenever possible. Building managers and maintenance personnel should be wary of requests for information about ventilation system details.

\subsubsection{Develop and train an emergency response team}

Any emergency requires rapid response in a number of areas, such as evacuation assistance, communication with authorities, and first aid/triage. A team of people with well-defined responsibilities should be created. Each team member should have a backup who can serve when the team member is not available. 
Among the responsibilities are: (1) main decision-making (such as, should the building be evacuated, should the HVAC system be turned off); (2) contacting authorities (e.g. fire department, police); (3) providing instructions to building occupants; (4) manipulating the HVAC system as needed; and (5) coordinating first aid.

\subsubsection{Establish external congregation areas}

For an indoor release, people should exit the building. The chem/bio agent will be carried out of the building through windows, doors, and vents, so people should congregate upwind of the building, at least $30 \mathrm{~m}(100 \mathrm{ft})$ away, preferably more.

At least two different evacuation zones should be identified in advance, and the appropriate one should be used depending on the wind direction.

\subsubsection{Plan and practice}

Plan and practice separate emergency response procedures for indoor and outdoor releases of chem/bio agents.

As discussed above, the first response to an outdoor chem/bio release should include shutting down the building's ventilation system and closing all doors and windows. In contrast, the response to an indoor chem/bio release may include manipulation of the HVAC system to provide uncontaminated air to people during evacuation and to prevent or slow the spread of the agent.

Building operators should understand the differences in the best responses to indoor versus outdoor releases, as discussed in this document, and should practice the steps they will take in each case. It is vital for the building operator to confirm that the HVAC operates as expected, and to fix any problems with the system that prevent its proper operation (see 7.1.2).

\subsection{Actions requiring changes to the building}

The following changes to a building could make it safer in the event of a chemical or biological attack. Some of these actions would require significant installation, maintenance, and/or operational expense. The level of threat, the costs, and the effectiveness of the changes being contemplated should be considered before implementing any very costly suggestion.

The recommended actions, described in detail below, are:

1. Provide secure access to HVAC controls;

2. Provide separate exhaust systems for high-risk areas;

3. Upgrade filters;

4. Establish internal safe zones;

5. Weatherize the building. 


\subsubsection{Provide secure access to HVAC controls}

There should be at least one secure location, safe from unauthorized intrusion, from which the whole HVAC system can controlled, so it is not necessary to move through a contaminated building to manipulate the system. Multiple control locations are desirable. These locations should include floor plans that show which ventilation zones are served by which air handling units.

At a minimum, the HVAC control location or locations should allow shutting off the HVAC (including closing dampers) and making the system deliver 100\% outdoor air. Ideally, the air handling units should be individually controllable, and additional fans such as kitchen and bathroom exhausts should be controllable from the same location.

Web-based tools may allow remote operation of the system from outside the building, although this raises its own security concerns. Rooms inside the building that allow HVAC manipulation should have the capability to be ventilated with $100 \%$ outdoor air; ventilation of these rooms with outdoor air should be optional, so that such ventilation can be shut off in the case of an outdoor release.

\subsubsection{Provide separate exhaust systems for high-risk areas}

Mailrooms, delivery areas such as loading docks, and areas with public access are the most likely locations for introducing toxic substances to a building. If the HVAC systems for these areas do not mix air into the rest of the building, the spread of the agent will be greatly reduced. Mixing into the general building air can be prevented either by providing a separate air-handling unit for these areas, or by eliminating return air for these areas and exhausting them directly. Contamination may still spread along hallways, etc., but this will usually be much slower, since air velocities in hallways are usually less than 0.1 meter per second.

Consider adjusting the HVAC supply and exhaust so that the high-risk areas are slightly de-pressurized with respect to the rest of the building, so that air will flow from other areas into the high-risk areas rather than the other way around.

An alternative to redesigning the HVAC system may be to reallocate activities among existing rooms. For example, if an existing room has return air registers that serve a larger area, that room can be made into the mail room, and its AHU can be set to provide no recirculation. In that configuration, contamination from the mailroom will not spread into the rest of the building. This might be cheaper and easier than re-fitting the existing mail room.

Exhaust without recirculation, a so-called "once-through" system, is very energy-inefficient because the energy used to bring outdoor air to the building's set-point temperature is lost when the air is exhausted, so the part of the building (if any) that is ventilated this way should be kept as small as possible. 


\subsubsection{Upgrade filters}

Most building HVAC systems have some type of particle filter. Substitution of a more effective filter (particularly for small particle sizes) can reduce the risk of spreading a biological agent through the building via the HVAC system. Most airborne biological agents are between 1 and 10 micrometers $(\mu \mathrm{m})$ in diameter, and virtually all are between $0.5 \mu \mathrm{m}$ and $15 \mu \mathrm{m}$. Most ventilation filters are very effective at removing particles larger than $10 \mu \mathrm{m}$; some filters are very effective at removing particles between 3 and $10 \mu \mathrm{m}$; only the best filters are very effective at removing particles smaller than $3 \mu \mathrm{m}$ (see [4]).

The American Society of Heating, Refrigerating, and Air Conditioning Engineers (ASHRAE) has developed a standard test procedure [2] for classifying filters using a Minimum Efficiency Reporting Value (MERV) - the higher the MERV, the better the filter. A filter with a MERV rating of 13 or higher, located so that it filters both recirculated air and air from the outdoor air intakes, will eliminate most biological agents from the HVAC supply air, if they are introduced upstream of the filter. A filter with a MERV rating of 9 or higher will be very effective at removing particles larger than about $5 \mu \mathrm{m}$, but the effectiveness falls off quickly with smaller sizes, and about $80 \%$ of $1 \mu \mathrm{m}$ particles will pass through such a filter.

Filters below MERV 10 should be upgraded. In the size range of airborne biological agents, each step upward in MERV rating has substantial benefits, up to about MERV 13. Beyond that, there is little benefit to filters with a higher MERV rating (including High Efficiency Particulate Air, or HEPA, filters).

More effective filters can lead to a significant pressure drop, which can pull unfiltered air around the filter or through leaks in ducts between the filter and the fan. To minimize or eliminate increases in pressure drop, deep pleated filters or filter banks with larger inlet area can be used if space allows. Improved filters can provide significant protection from a biological release, but they should be installed correctly and duct leaks should be sealed to reduce air bypass.

Installing new filters may require changes in other equipment too (e.g. fan capacity may need to be increased), in order to maintain air quality and comfort, and may increase energy use, so it should be done only after careful evaluation.

\subsubsection{Establish internal safe zones}

Establish internal and external safe zones for people to use during a toxic release. For an outdoor release, people should remain indoors. "Shelter-in-place" rooms can be created or identified, where people can stay in the event of an outdoor release. The goal is to create areas where outdoor air infiltration is very low. Usually such rooms will be in the inner part of the building (no windows to the outside). They should have doors that are fairly effective at preventing airflow from the hallways: at least there should be no gap around the edges of the door, and preferably there should be a gasket to completely seal the room.

Bathrooms are usually a bad choice, because they often have an exhaust duct that leads directly to the outside. If the exhaust fan is turned off, then the duct, which leads directly outside, can allow toxin-bearing outside air to directly enter the bathroom, which could be very 
harmful during an outdoor release. Additionally, the stack effect can draw air into the bathroom from within the building, eventually contaminating the building during an indoor release. If the exhaust fan is left on then air will be drawn into the bathroom from other parts of the building, which will eventually contaminate the bathroom.

Exhaust fans for bathrooms and utility rooms are often controlled separately from the HVAC system.

Opening and closing a conventional door can pump significant amounts of air into the safe room: Kiel and Wilson [5] report that each time the door opens and closes, about 50\% of the volume swept by the door can be pumped into the room. Replacing the door with a sliding door, if practical, can substantially reduce this effect.

Additionally, it may be possible to provide purified air to the safe area, depending on whether the pollutant can be removed by the building's air filtration system. Modifications to the HVAC system can add special chemical and biological filters to the air supply for the safe area. Pressurizing the safe zone with purified air will greatly reduce entry of contamination, and will also reduce the importance of construction details such as the size of the cracks around the door.

\subsubsection{Weatherize the building}

"Weatherize" the building by sealing cracks around doors and windows.

Cracks around windows and doors allow conditioned air to escape the building, and outdoor air to enter. Sealing these gaps can reduce the amount of flow between the building and the outside, thus improving energy efficiency, and slowing the rate at which contamination enters the building from the outdoors.

In large buildings subject to very cold weather, reducing the leakiness of the upper floors can greatly reduce flows caused by the stack effect [9]; such reduction is desirable because such flows can transport contamination rapidly through the building, and can contaminate stairwells that are needed for evacuation.

Many large buildings have a small exterior-surface-to-volume ratio. In such buildings, weatherization is unlikely to have a large effect on reducing casualties from an outdoor chem/bio release. On the other hand, this improvement might pay for itself in a few years through reduced energy cost, and improve occupant comfort (especially in the offices on the perimeter of the building), in addition to potentially improving safety for a chem/bio attack. Details of the cost-benefit trade-off will depend on construction details (such as the leakiness of the building shell), local energy costs and climate, and other factors. 


\section{Chapter 8}

\section{Concluding comments}

The advice presented in this paper comprises our recommendations as of its publication date. We are very confident in our recommendations for preparing for an attack (although we may add more), but we are still considering some of the recommended actions during an attack. It is easy to come up with scenarios in which any particular piece of advice is bad, and all of the advice involves assessment of what scenarios are most likely to occur. The advice in this paper is based on our current assessment.

Our current research on airflow in buildings may lead us to offer different advice, as may work done by others or evaluation of (past or future) biological or chemical releases in buildings. For our latest advice and information, see http://securebuildings.lbl.gov 


\section{Appendix A}

\section{Facts about chemical warfare agents}

Most chemical warfare agents are liquid at room temperature. The most effective distribution of these agents requires aerosolizing (distributing the liquid in the form of tiny droplets, as from a spray can) or vaporizing (heating the agent so it evaporates). Evaporation from a puddle of liquid is much less effective, but can still be fatal; in 1995, intentional spills of liquid Sarin in several Tokyo subway stations injured 5500 people, killing 11.

Some chemical warfare agents have a color in liquid form, but once vaporized or aerosolized all agents are fatal even in concentrations that are invisible in air.

Some chemical agents (e.g. sarin) are odorless, but many do have an odor, though often not a "chemical" odor. For example, Tabun smells fruity; Mustard Gas smells like garlic, onion, or mustard; Lewisite smells like geraniums; Phosgene smells like grass or hay.

Some chemical warfare agents can be absorbed through skin.

Some chemical warfare agents are heavier than air; most others are approximately neutrally buoyant. Staying close to the floor, as recommended for smoke, will not reduce exposure, and may increase it.

For information about specific agents, how to treat them, and how to recognize them, see the First Responder Chem-Bio Handbook [14] or Jane's Chem-Bio Handbook [8]. 


\section{Appendix B}

\section{Facts about building operation}

As of May, 2002, the following web sites contain information and advice for responding to a chemical or biological release:

- The American Society of Heating, Refrigerating, and Air-Conditioning Engineers (ASHRAE) [http://www.ashrae.org], is a good source of information about buildings and building technology.

- The U.S. Army Edgewood Chemical Biological Center and the Army Corps of Engineers Protective Design Center [http://buildingprotection.sbccom.army.mil/basic] has some useful information, including a document on how to prepare for a chem-bio attack. The report emphasizes pre-event planning, but also gives advice on action to take during an event. Some of the advice differs from ours.

- The National Institute for Occupational Safety and Health (NIOSH) [ http://www.cdc.gov/ niosh/], part of the Centers for Disease Control (CDC), has issued guidance for protecting buildings from an airborne chemical, biological, or radiological attack.

- A new supplement to the Federal Emergency Management Agency1s (FEMA) Guide for All-Hazard Emergency Operations Planning: State and Local Guide has been produced to help state and local emergency planners develop and maintain terrorism annexes to their emergency plans [http://www.fema.gov/]. FEMA also has some information at their Hazardous Materials Guide for First Responders web site [ http://www.usfa.fema.gov/hazmat/ trainresp.htm].

The following four pages constitute the "Information for First Responders" guide mentioned in section 2.1, which provides some simple information about HVAC design and operation for typical commercial buildings. The two subsequent pages give "Advice for Building Operators and Incident Commanders," emphasizing actions rather than general building knowledge. Current versions of these documents are available at http://securebuildings.lbl.gov. 



\section{First Responders to an Indoor Chemical Release Ventilation System ON}

1. If supply air becomes contaminated, contaminant will spread rapidly through the entire ventilation zone: every supply register in that zone becomes a source. This can happen:

(a) if contaminated outdoor air enters the intake.

(b) if contaminant-bearing air from inside the building is recirculated.

2. Most commercial buildings recirculate indoor air, if outdoor air is hot or cold. In this case, supply air (into the building) will eventually become contaminated, so the pollutant will spread everywhere.

Normal Operation:

Some Recirculation

Supply Air Becomes Contaminated

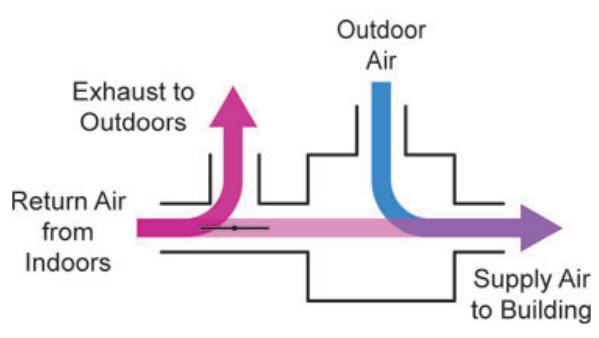

(a) Most ventilation systems supply a mix of outside air and recirculated (return) air.

(b) In extreme hot and cold weather, the mix shifts to higher recirculation.

(c) In mild temperatures $\left(55-70^{\circ} \mathrm{F}\right)$, some buildings take in as much outdoor air as possible.

3. The ventilation system causes large air flows that move contamination through the building.

A ventilation zone may cover a large or small area, and may mix air between floors.

(a) A ceiling air return plenum may serve a single room or a large zone; contaminated air can be pulled along in the plenum and may quickly enter the supply air (1-10 min.)

(b) If a contaminated room has a "ducted return", contaminated air will probably enter the supply air very rapidly (20 sec - $3 \mathrm{~min}$ ).

(c) If supply air is contaminated, contamination will spread throughout the whole ventilation zone rapidly (seconds or minutes): Every supply register in the zone becomes a source.

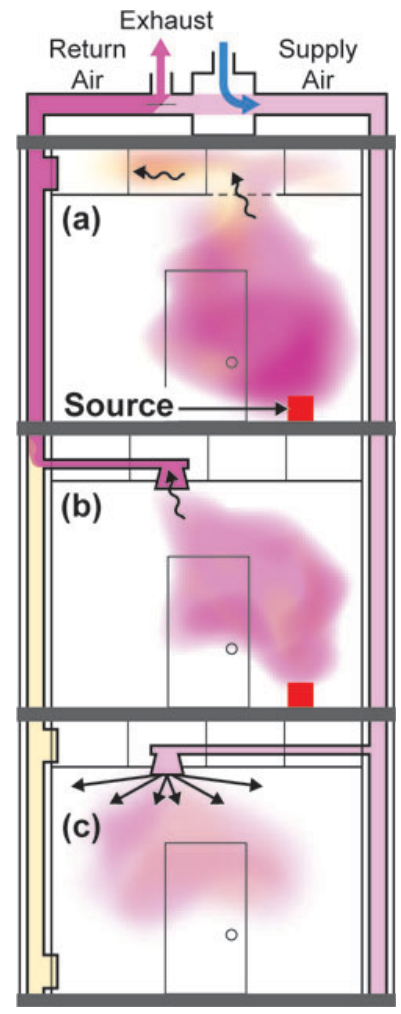




\section{First Responders to an Indoor Chemical Release Ventilation System ON}

4. A return air grille in a hallway can draw contaminated air into and along the hall, even if doors are closed.

Contaminated air may enter supply air via recirculation (see item 1) in 1-10 minutes.

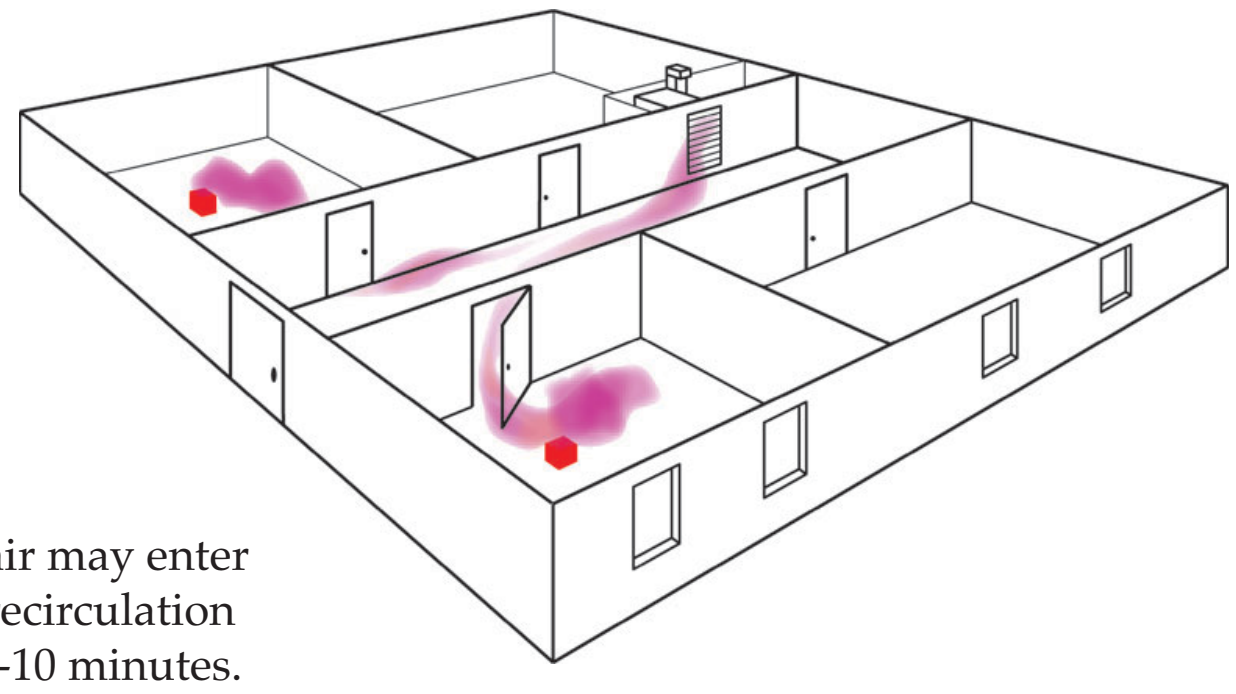

5. A stairwell, elevator shaft, or utility chase can provide a pathway for flow between floors. The ventilation system can force airborne contaminants to flow either up or down.

A moving elevator creates a piston effect that can force contaminatation to flow up or down.

Flows can be significant even if elevator doors and stairwell doors are closed.

Unlike smoke, contaminants can be either heavier or lighter than air, and so can sink or rise even in still air.

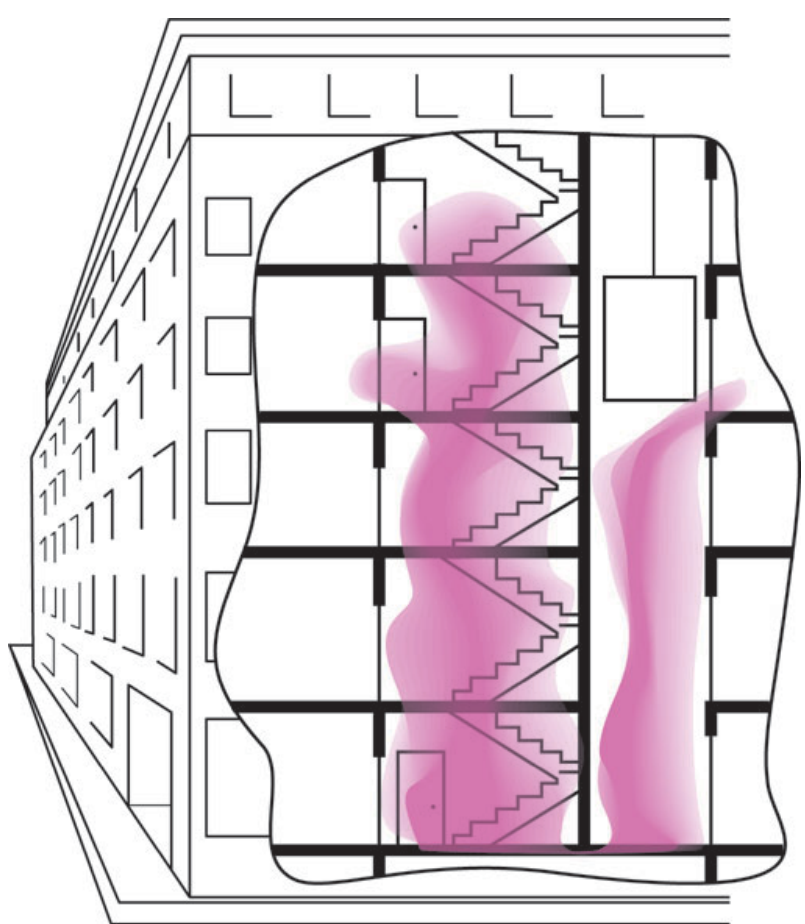




\section{First Responders to an Indoor Chemical Release Ventilation System OFF}

1. Effects that can be ignored when the ventilation system is on, become dominant when it's off. Examples are wind leaking into the building, drafts, and buoyancy (warm air rises, cool air sinks).

2. Air flows are generally slower than when the ventilation system is on. Ventilation ducts provide pathways for contamination to flow between rooms and floors, even with the ventilation system turned off.

Temperature and pressure differences can drive flow upward or downward between floors. Contaminant can flow from room to room, for example:

(a) horizontally through ducts

(b) vertically through ducts or other openings

(c) through the ceiling plenum

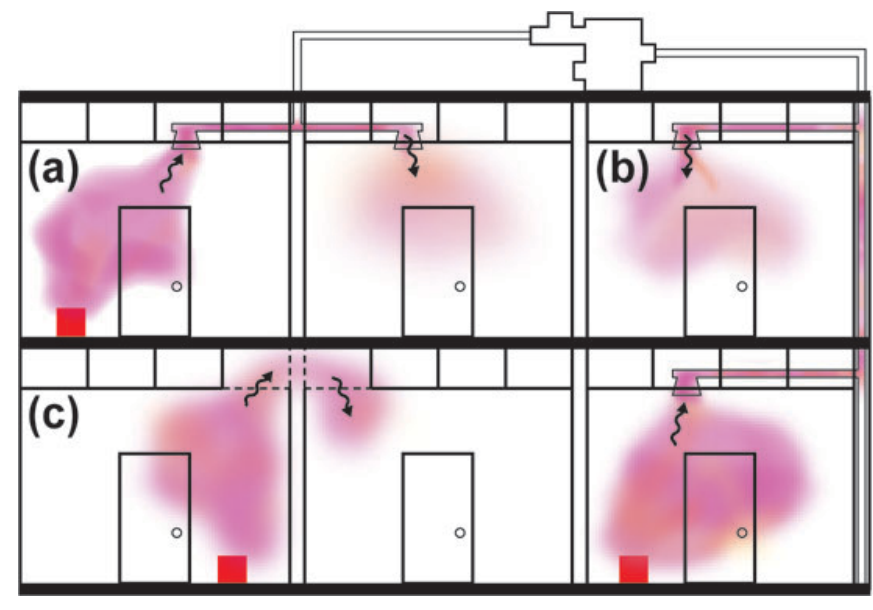

3. Flows depend strongly on wind and on the indoor-outdoor temperature difference, especially when windows are open.

Outdoors Warmer:

Indoor air, which carries the contamination, tends to descend as it leaks from the building.

Outside air enters upper floors. Some

contamination may still move upwards due to local flows or drafts.

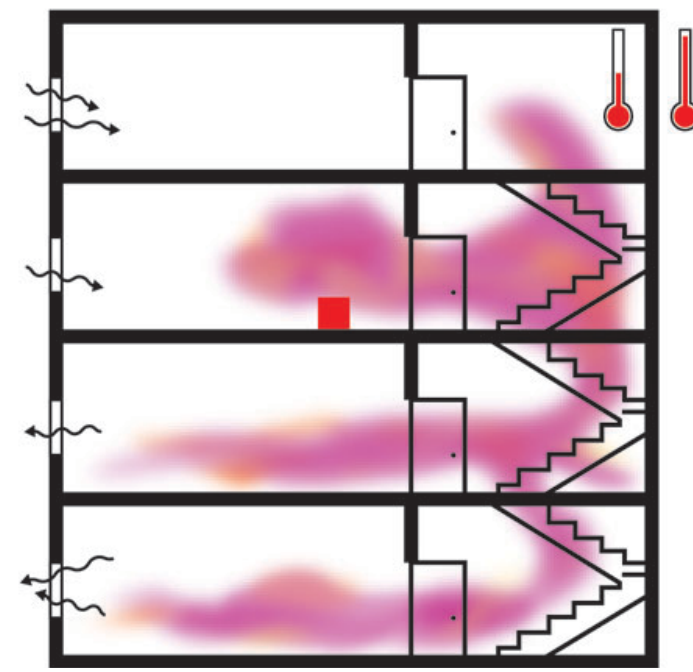

\section{Outdoors Cooler:}

Indoor air, which carries the contamination, tends to rise as it leaks from the building. Outside air enters lower floors. Some contamination may still move downwards due to local flows or drafts.

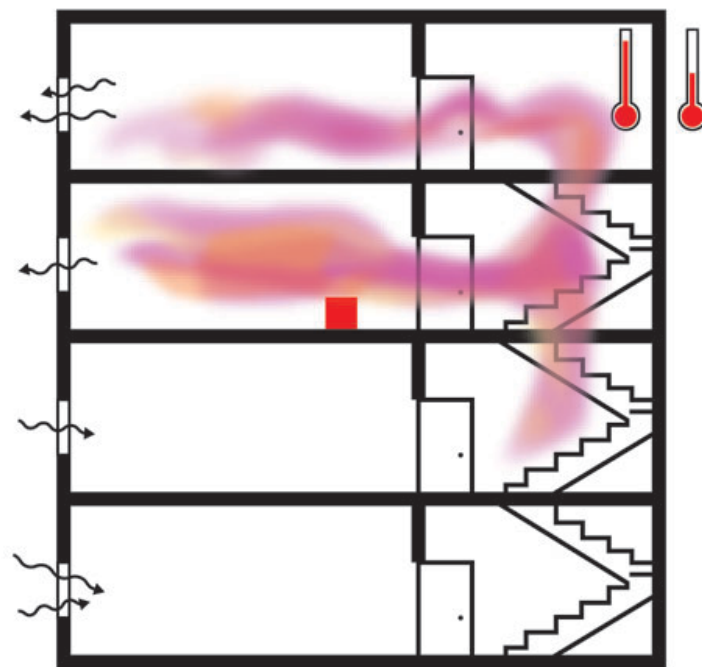




\section{First Responders to an Indoor Chemical Release Ventilation System OFF}

4. Fast or strong vertical flows can occur through elevator shafts, stairwells, utility chases, and other connections between floors.

Horizontal flows are usually weaker than vertical flows, except when there are strong winds or other causes of horizontal pressure differences.

Unlike smoke, contaminants can be either heavier or lighter than air, so they can sink or rise even in still air.

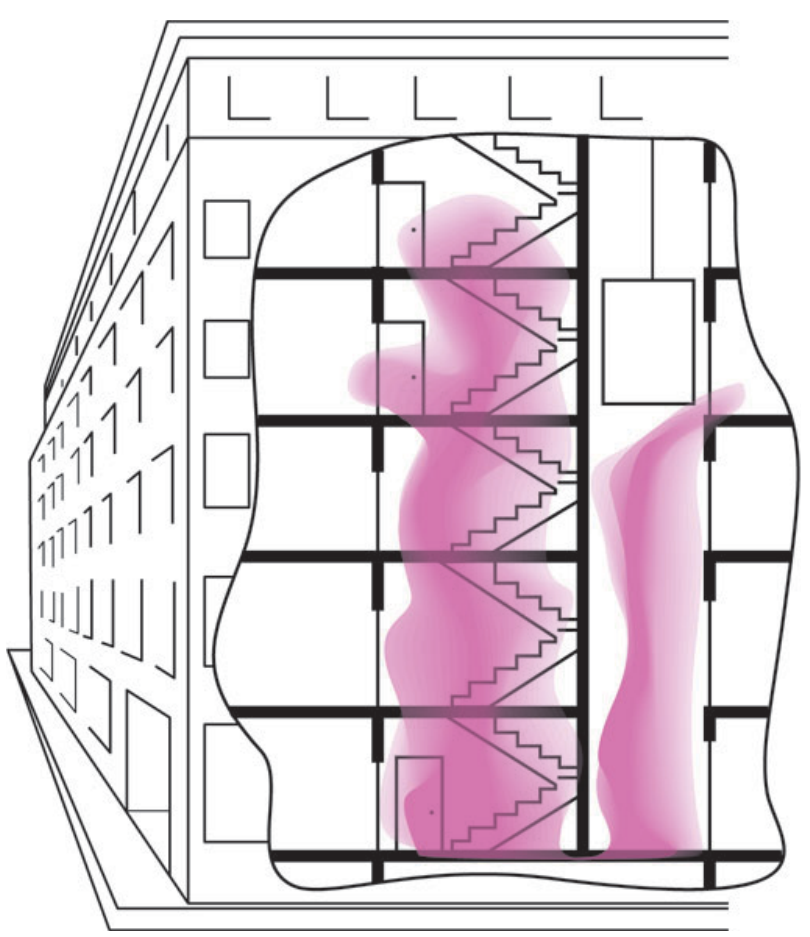

For more information see

http://SecureBuildings.lbl.gov

or contact

Dr. Phillip Price

Lawrence Berkeley National Lab

1 Cyclotron Road

Mailstop 90-3058

Berkeley, CA 94720

PNPrice@lbl.gov

Place Stickers Here with

Local Emergency Numbers 


\section{Building Operators and Incident Commanders Response to an Indoor Chemical Attack}

\section{Unless a knowledgeable building operator is present:}

- Leave the HVAC system operating as is.

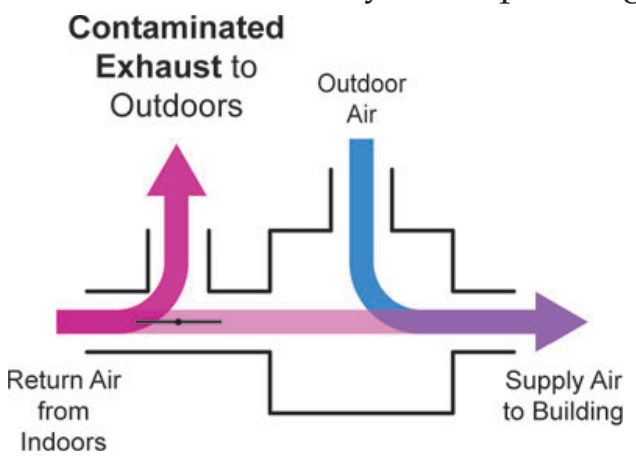

Under normal operation, the HVAC system will exhaust contaminated air from the building, and replace it with fresh air.

WARNING: a plume of contamination will spread downwind from the building's exhaust vents.

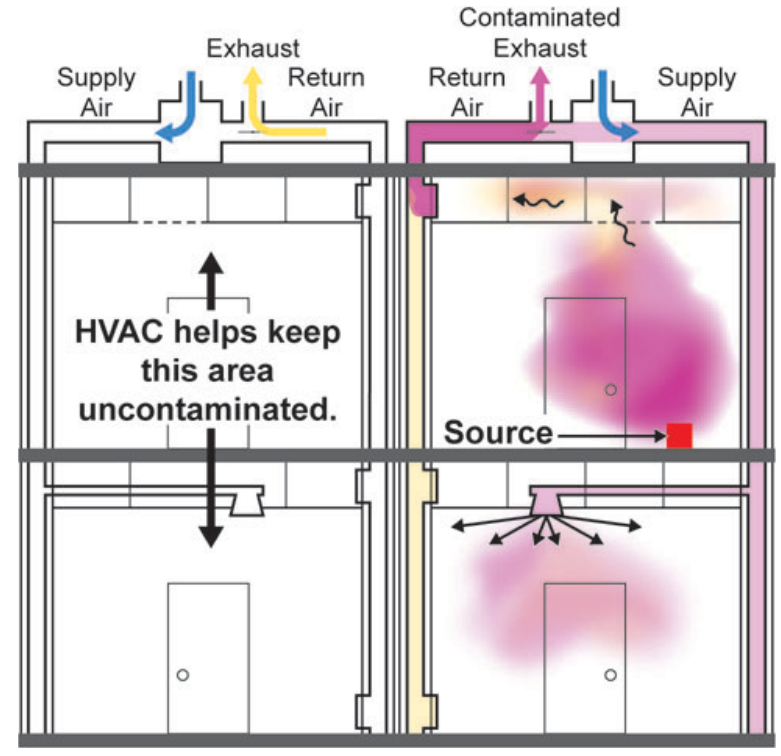

Continued HVAC operation may slow chemical spread between areas served by different air handling units, and help prevent contamination of stairways and hallways.

\section{If a knowledgeable building operator is present:}

- Set fans and dampers to deliver 100\% outdoor air at maximum volume (see note 1 below).

- If a release into one or more of the building's air intakes is suspected, shut off supply from the contaminated air intakes.

If more sophisticated actions are possible:

- Pressurize stairwells with $100 \%$ outdoor air (see note 2).

- Put the air handlers serving heavily contaminated areas onto full exhaust (see note 3 ).

- Shut off supply to contaminated areas (see note 3 ).

- Provide 100\% outdoor air to uncontaminated areas and areas with people.

Notes:

1) Delivering 100\% outdoor air will provide safe air to occupants and will exhaust the chemical quickly.

2) Pressurizing stairwells with $100 \%$ outdoor air will help provide a safe evacuation route.

3) Exhausting contaminated areas and supplying fresh air to uncontaminated areas helps ensure that air does not flow from contaminated areas to safe areas.

4) Depending on the HVAC design, some of the more sophisticated actions may be achieved by putting the building into "smoke removal" mode.

If safely possible, evacuate people from the building to a meeting point upwind of the building. Visit http://securebuildings.lbl.gov for more information and updates. 


\section{Building Operators and Incident Commanders Response to an Indoor Biological Attack}

\section{It is critical to find and treat everyone who has been exposed.}

To help prevent exposing people outside the building:

Shut off the HVAC system.

Close intake and exhaust dampers (or, if this is not possible, set them for full recirculation). Leave HVAC off.

- Shut off local exhausts, such as those serving bathrooms and kitchens. They are often controlled separately from the HVAC system.

To help reduce exposure of building occupants:

- Pressurize stairwells with $100 \%$ outdoor air if possible, to provide an evacuation route.

Segregate people known to be exposed, to avoid contaminating others via contact with clothes or skin, and tag or mark these people for medical treatment and decontamination.

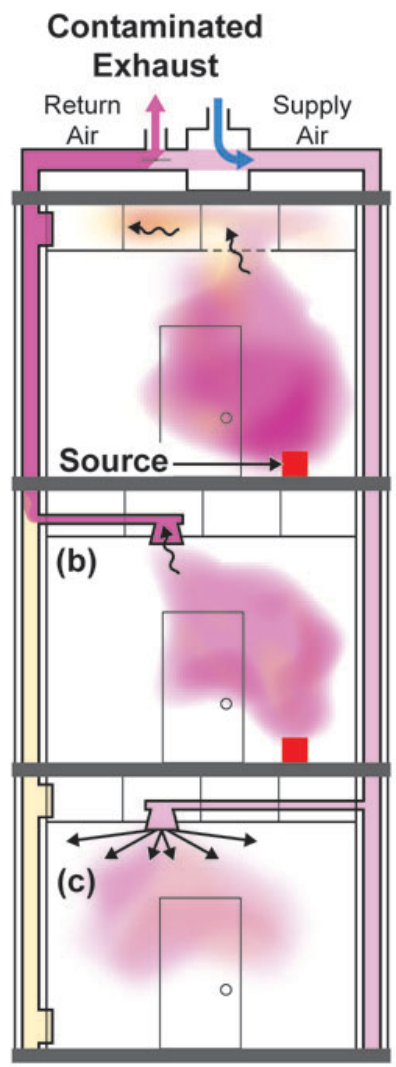

Normal HVAC operation releases contaminated air to the outdoors.

- If possible, evacuate people from the building to a meeting point upwind of the building.

\section{Notes:}

1) Pressurizing stairwells with fresh air will help keep contaminated air from entering the stairwells.

2) Everyone exposed should receive treatment, as symptoms may not appear for several days. 


\section{Bibliography}

[1] American Society of Heating, Refrigerating, and Air-Conditioning Engineers, 1995 ASHRAE Handbook on HVAC Applications, 1995.

[2] American Society of Heating, Refrigerating, and Air-Conditioning Engineers, Method of Testing General Ventilation Air Cleaning Devices for Removal Efficiency by Particle Size, 2001.

[3] California Commission on Peace Officer Standards and Training, Law Enforcement Response to Weapons of Mass Destruction, Post.TDB.2002-02, 2002.

[4] Fisk, W.J., Faulkner, D., Palonen, J., and Sappanen, O., Performance and costs of particle air filtration technologies, Indoor Air 12:223-234, 2002.

[5] Kiel, D.E. and Wilson, D.J. 1989. Combining door swing pumping with density driven flow. ASHRAE Transactions. Vol. 95(2):590-599, 1989.

[6] National Institute for Occupational Safety and Health, Guidance for Protecting Building Environments From Airborne Chemical, Biological, or Radiological Attacks, 2002.

[7] Greenwood, D.P. A Relative Assessment of Putative Biological-Warfare Agents, Lincoln Laboratory, Massachusetts Institute of Technology, Technical Report 1040, July 1997.

[8] Sidell, F.R. Jane's Chem-Bio Handbook, Surrey, United Kingdom, 1998.

[9] Lovatt, J.E., Stack Effect in Tall Buildings, ASHRAE Transactions 100(2):420-431, 1994.

[10] Rock, B.A., and Moylan, K.A., Placement of Ventilation Air Intakes for Improved IAQ, ASHRAE Transactions 105(1):71-79, 1999.

[11] Seem, J. E., House, J.M., Kelly, G.E., Klaasen, C.J., A Damper Control System for Preventing Reverse Airflow Through the Exhaust Air Damper of Variable-Air-Volume Air-Handling Units, International Journal of HVAC Research, 6(2), 2000.

[12] Seem, J. E., House, J.M., and Klaasen, C.J., Volume Matching Control: Leave the Outdoor Air Damper Wide Open, ASHRAE Journal, 40(2):58-60, 1998.

[13] Seinfeld, John H., Atmospheric Chemistry and Physics of Air Pollution, Wiley and Sons, New York, 1986.

[14] First Responder Chem-Bio Handbook, B.N. Venske, editor. Tempest Publishing, Alexandria, Virginia, 1998. 
[15] U.S. Army Edgewood Chemical Biological Center and the Army Corps of Engineers Protective Design Center, Protecting Buildings and Their Occupants from Airborne Hazards, Technical Instruction 853-01, October 2001. 


\section{Index}

air exhaust

prevent access, 28

air intake

prevent access, 28

release into, 25

biological release

distinguishing from chemical, 11

indoor, 15,17

outdoor, 13

building operators

advice document for, 42

chemical agents

facts about, 35

chemical release

distinguishing from biological, 11

indoor, 15, 22

outdoor, 13

congregation areas, 30

definitions of terms, 6

evacuation, 15

exposed people

minimizing number, 17

minimizing total exposure, 22

segregating, 20

filters

role during indoor biological release, 19

role during outdoor biological release, 14

upgrading, 32

first responders

informational document for, 37

HVAC

continued operation during indoor chemical release, 23

definition, 7

manipulation during indoor biological release, 18

manipulation during indoor chemical release, 24

plans, 29

prevent access, 29

upgrade and maintain, 28

incident commanders

advice document for, 42

indoor release

biological, 17

biological or chemical, 15

chemical, 22

outdoor release

biological or chemical, 13

preparation

establish external congregation areas, 30

establish internal safe zones, 32

HVAC system, 28

modifying the building, 30

plan and practice, 30

response team, 29

separate HVAC for high-risk areas, 31

upgrade filters, 32

weatherize, 33

safe zones, 32

smoke

difference between chemical and, 25

smoke removal system, 25

stack effect, 23

definition, 7

stairwells

pressurizing during biological release, 20

pressurizing during chemical release, 25

ventilation zone

definition, 7

isolating, 25 